\title{
REVISTAMARACANAN
}

Artigos

\section{Trilhas lusitanas pelo Rio da Prata: redes mercantis e tramas sociais na Buenos Aires colonial (Século XVII) ${ }^{1}$}

\author{
Lusitanian trails by Rio da Prata: \\ commercial networks and social ties \\ in colonial Buenos Aires (17th Century)
}

Rodrigo Ceballos

Universidade Federal de Campina Grande rcovruski@yahoo.com.br

\begin{abstract}
Resumo: Apesar das proibições régias, a cidade de Trinidad y puerto de Buenos Aires recebeu, ao longo da primeira metade do século XVII, a entrada de portugueses. A intensidade de tratos e contratos de portos da América portuguesa (especialmente da Bahia) com o porto de Buenos Aires propiciou um lucrativo comércio de escravos e contrabando de metais preciosos. Por meio das atas do Cabildo da cidade, residências e visitas dos navios registradas pelos oficiais régios do Rio da Prata, nota-se a formação de complexas redes de privilégios envolvendo seus camarários, oficiais régios, governadores e lusitanos residentes ou não naquela localidade. Este artigo objetiva delinear, a partir das trilhas deixadas por influente negociante português, algumas estratégias de inserção lusa e participação em bandos numa Buenos Aires marginal à América espanhola.
\end{abstract}

Palavras-chave: Rio da Prata; Redes sociais; Comércio.

\begin{abstract}
Despite the royal prohibitions, the city of Trinidad $y$ Puerto de Buenos Aires received during the first half of the 17 th Century great Portuguese arrivals. The business intensity among American Portuguese ports (especially of Bahia) and Buenos Aires provided a lucrative slave trade and precious metals smuggling. By the analysis of the Atas of the Cabildo (minutes Council), residencias (residences) and ships visits registered by Rio da Prata's royal officers we realized a complex privileges networks involving their municipal officers, royal officers, governors and Lusitanian residents (or not) in that locality. This paper aims to outline, from the trails left by an influential Portuguese trader, some of the Portuguese strategies of integration and participation in bandos (groups) in a peripheral Buenos Aires in Spanish America.
\end{abstract}

Keywords: Rio da Prata; Social networks; Commerce.

Artigo recebido para publicação em: Fevereiro de 2016 Artigo aprovado para publicação em: Abril de 2016

${ }^{1}$ Este artigo é resultado de pesquisa de doutoramento financiada pelo CNPq. 

o primeiro semestre de 1641, o Cabildo (Senado da Câmara) de Buenos Aires recebeu a notícia do alzamiento (Restauração) de Portugal e a nomeação do duque de Bragança como monarca rebelde da Espanha. Temerosos de um provável ataque vindo do Brasil, os regidores (oficiais camarários) do Cabildo concordaram com a argumentação do seu teniente de gobernador sobre a fragilidade do porto, sem pólvora e munições para sua defesa. ${ }^{2}$ No mesmo ano, promulgou-se a Cédula Real que reforçou a proibição de portugueses ocuparem cargos públicos, de comercializarem e fixarem residência em terras espanholas. Aos que já residiam nas cidades hispano-americanas costeiras era "conveniente y necesario [...] aún que estén avecindados, casados o por casar y hallan comprado oficios publicos sean retirados veinte o más leguas la tierra adentro $[\ldots]^{\prime \prime} .^{3}$

O governador do Rio da Prata falecera em dezembro de 1640, antes da chegada da notícia do fim da união das coroas ibéricas. Coube ao seu substituto interino, o teniente de gobernador Pedro de Roxas y Acevedo (com cargo militar capaz de representar a administração régia em caso de ausência do governador), tomar as decisões cabíveis para a defesa da terra. Situação ambígua esta, pois o número de lusitanos no porto ou com algum vínculo com os moradores da região rio-platense não deixa de impressionar. Em 1641, haveria em torno de 500 lusitanos sem residência fixa na cidade de Buenos Aires, sendo 270 deles homens de "mar en fuera" (provavelmente marinheiros); e ao menos 70 portugueses eram chefes de família, com terras na região. ${ }^{4}$

O próprio governador interino Roxas y Acevedo era o genro de um deles: o respeitado vecino comerciante Diego da Vega. ${ }^{5}$ Estabelecido na cidade desde a primeira década de 1600 , Vega era feitor de asientistas de escravos, com sociedades comerciais no interior do Rio da Prata e Tucumán. Obteve prestígio local graças a aliança com o espanhol Juan de Vergara, teniente de gobernador da província em 1609. Devido ao apoio do Cabildo, foi o comprador de seis cargos camarários em Buenos Aires para a livre distribuição aos seus amigos e aliados, entre eles um lusitano.

A influência local de Vega, com suas relações parentais e alianças comerciais, propiciaram o aceite do Cabildo ao seu pedido de vecindad, tornando-o um morador com registro em Buenos Aires. Com isso, ele obteve o direito à caça do gado selvagem na região

\footnotetext{
${ }^{2}$ Cabildo del 16 de abril de 1641 e Cabildo del 8 de agosto de 1641. In: BIEDMA, Jose Juan. Acuerdos del Extinguido Cabildo de Buenos Aires. Libros V y VI (1640-1645). Buenos Aires: Talleres Gráficos de la Penitenciaria Nacional, 1911. Tomo 9. p. 135 e 170-172.

${ }^{3}$ Real Cédula de 7 de Enero de 1641, prohibiendo el avecindamiento de portugueses en las colonias de España. In: Archivo de la Nación Argentina. Reales Cedulas y Provisiones (1517-1662). Buenos Aires: Talleres Gráficos de la Penitenciaria Nacional, 1911. Tomo 1. p. 257.

${ }^{4}$ Archivo General de Indias, Escribanía de Cámara y Justicia del Consejo de Indias, Residencias de la Audiencia de Buenos Aires, Escribanía, 892C - "Luis Gomes de Sossa vecino de esta ciudad de la Trinidad puerto de Buenos Aires, en nombre de los portugueses [...]", 1647.

${ }^{5}$ Vecino (vizinho) era um termo hispano-americano empregado aos moradores (cidadãos) detentores de privilégios locais, com suas distinções e honrarias. A partir da segunda metade do século XVII, especialmente em áreas periféricas como Buenos Aires, o direito de vecindad foi adquirido e mantido por mestiços (criollos) representantes de uma elite local.
} 
(cimarrón), de ter propriedades e solares na cidade, de comerciar e, especialmente, o direito de voto e ocupar cargos administrativos na cidade.

Mas Diego da Vega teve uma participação discreta na política local, tornando-se, por decisão do Cabildo, no mayordomo (administrador) do hospital da cidade. É o seu tino comercial que está melhor descrito na documentação. Por isso, não seria muito especular sobre a importância do hospital mantido por ele, localizado ao sul da cidade e a poucos quilômetros do rio Riachuelo (atual bairro do Boca, de Buenos Aires). Era um espaço estratégico capaz de armazenar mercadorias que viessem clandestinamente pelo pozo do rio. ${ }^{6}$ Vega também possuía terras próximas ao Riachuelo, servindo como apoio para o desembarque de escravos. Por volta de 1622, quando Diego da Vega fixou definitivamente residência em Lisboa, deixou para seus parentes aproximadamente 20 estâncias, com 50 escravos cada. ${ }^{7}$

Não eram raras as denúncias de que Vega se aproveitasse de suas propriedades para esconder africanos escravizados. Em 1613, o português, mestre de navio, Antonio González Roda, transportou desde as "costas do Brasil" a Buenos Aires, com as mercadorias do vecino Diego da Vega, 10 ou 12 escravos ilegais que foram levados às casas do também vecino comerciante português Antonio Fernandez Barrios e do próprio González Roda. ${ }^{8}$ Dias depois, tornou-se público que ao menos cinco daqueles escravos estavam em uma das chácaras de Vega.

A partir dos tratos e contratos do mayordomo Diego da Vega no porto semiaberto de Buenos Aires e suas ligações ultramarinas e inter-regionais, rumo a Potosí, percebe-se a dificuldade em discernir a existência de um grupo contrabandista português apartado de interesses de moradores da América espanhola, de oficiais régios e, até mesmo, governadores. Este breve artigo busca delinear, a partir de fontes documentais que envolvem o nome deste vecino lusitano, algumas redes comerciais luso-espanholas entre portos das "costas do Brasil" e o porto de Buenos Aires, e a dificuldade em delimitar a existência de lusitanos no Rio da Prata unicamente interessados no contrabando e tráfico de escravos. O comércio serviu de pano de fundo para o estabelecimento de uma dinâmica social muito mais intensa, construtora

\footnotetext{
6 Para evitar o contrabando de metais preciosos, escravos e mercadorias com a América portuguesa e a África, a coroa espanhola proibiu o livre comércio no porto de Buenos Aires a partir do ano de 1594. Apesar das Cédulas Reais permissionárias de 1602, 1618 e 1622 reabrirem o comércio com frutos de la tierra (especialmente farinha, carne-seca e sebo), o trato no porto permaneceu restrito. A prioridade comercial repousava na manutenção da rota das flotas y galeones, contribuindo para o desenvolvimento do monopólio comercial de Lima, capital do vice-reino do Peru. Real Cédula de 20 de agosto de 1602, permitiendo la exportación de frutos al Brasil y Guinea. In: Archivo de la Nación Argentina. Reales Cedulas y Provisiones (1517-1662), Tomo 1, Buenos Aires, 1911. p. 52-53. Ver também: CANABRAVA, Alice P. O comércio português no Rio da Prata (1580-1640). Belo Horizonte: Itatiaia; São Paulo: Edusp, 1984. p. 71-78.

7 MOLINA, Raúl A. Juan de Vergara, señor de vidas y haciendas en el Buenos Aires del siglo XVII. Boletín de la Academia Nacional de Historia, v. XXIV-XXV, 1950-1951, 72-124.

8 Antonio Fernandez Barrios costumou comercializar escravos em Buenos Aires na primeira metade do século XVII. Era proprietário dos navios San Antonio e Nuestra Señora del Buen Viaje com os quais mantinha contatos comerciais com portos da América portuguesa e transportava, além de escravos, vinhos, sal e conservas. TRELLES, Manuel Ricardo. Registro y desarme de portugueses. Revista del Archivo General de Buenos Aires, Tomo 3, 1865, 142-263.
} 
de redes de privilégios na marginal cidade portuária capazes de garantir, por exemplo, cargos militares ou civis a vecinos portugueses.

Apesar da importância do estudo da participação lusitana no porto de Buenos Aires por meio do contrabando e da cultura material na cidade, preferimos também deter-nos naqueles personagens históricos que se casaram com criollas, obtiveram solares, chácaras para trabalhar e cuidar do gado, o direito de exploração de mão de obra nativa e foram, até mesmo, regidores.

Nome histórico conhecido e representativo da amplitude dessa presença lusitana no Rio da Prata e no seu interior foi o de Diego López de Lisboa. Este comerciante chegou a Buenos Aires por volta de 1596 e, cinco anos depois, era encomendero na cidade de Córdoba, província de Tucumán. Foi pai de António de León Pinelo, futuro jurista, organizador da Recopilación de Leyes de las Índias e defensor do comércio de Buenos Aires com o Estado do Brasil, Angola e Sevilha. ${ }^{9}$ Com o falecimento de sua esposa, Diego López transferiu-se para Potosí e, sem perder os contatos comerciais de Buenos Aires, enriqueceu com o comércio no porto. ${ }^{10}$

López de Lisboa era parente de Diego da Vega e tinham uma sociedade no contrato de africanos escravizados. No ano de 1615, o asiento foi obtido perante o reino de Castela pelo lusitano Antonio Fernandes d'Elvas. Mantendo atada a rota de escravos com o porto de Buenos Aires, d'Elvas confiou justamente a Diego da Vega o cargo de feitor. E, em caso de sua ausência, o poder deveria ser repassado a Manuel de Vasconcelos, um conhecido traficante de escravos, ou ao próprio Diego López de Lisboa. ${ }^{11}$ Este, junto com o irmão de Vega, Duarte

\footnotetext{
${ }^{9}$ Em 1623, António de León Pinelo levou ao Conselho das Índias, em nome do Cabildo, seu memorial em defesa de Buenos Aires, Córdoba e Potosí. Pinelo preocupou-se em levantar os serviços prestados pelos vecinos e mostrar a necessidade imediata de mercê real pelos convenientes e vantagens comerciais que o porto no Rio da Prata poderia proporcionar à coroa. Pedia licenças perpétuas para transportar, sem limite, couros à Sevilha e carne-seca, sebo e farinha ao Estado do Brasil e a Angola. No retorno, as embarcações transportariam produtos manufaturados e escravos, podendo ainda ser comercializada a prata. In: MOLINA, Raúl A. António de León Pinelo y su vida en América. Su testamento y su obra. Boletín de la Academia Nacional de Historia, v. XXIV-XXV, 1950-1951, 453-504.

10 Diego López de Lisboa também acompanhou seus filhos à Universidade de Lima, tornando-se licenciado em Charcas, além de padre e mayordomo do bispo de Lima, Fernando Arias. Id. HANKE, Lewis. The portuguese in Spanish America, with special reference to the Villa Imperial de Potosí. Revista de Historia de América, junho, n. 51, 1961, 1-48.

${ }^{11}$ A escritura de poder do asientista d'Elvas declarava a Vega, López de Lisboa e Vasconcelos como "[...] factores y administradores del asiento de las licencias de Indias en las provincias del Perú y del Río de la Plata y puerto de Buenos Aires para que por mi y en mi nombre y como yo mismo representando mi persona puedan haber recibir y cobrar hayan reciban y cobren a su poder todos los esclavos que se llevaren conforme a las Cedulas y ordenes que para ello tengo de Su Majestad llevándolos a las dichas provincias y así mismo para que lo puedan vender y vendan al fiado o al contado así en el dicho puerto como trajinándolos y enviándolos a otros cualquier puertos y venderlos en los precios que les pareciere y cambiarlos a frutos de la tierra como en otras cualesquier mercadurías y enviarme por mi riesgo y cuenta todo lo procedido y que procediere de los dichos esclavos en que hubieren vendido y arrebatado o recompensa de ellos por todas las vías que pudieren así por la de Potosí como por otras partes para que vengan en flotas o navíos de permisión y en otros cualesquier navíos que vinieren a estos reinos de los dichos puertos en conformidad del dicho asiento y Cedulas Reales de Su Majestad despachadas en mi favor para todo lo cual y demás que se ofrezca y fuere necesario quedan así en lo tocante a lo sobre dicho como en hacer y procurar que no se lleven ningunos negros por ninguna vía más de los que manda Su Majestad en conformidad de sus reales cedulas y porque llevándose algunos más los hagan denunciar y denuncien ante la justicia aplicándolos para mi y los vendan y hagan vender por el precio y precios que les parecieren y requerir y protestar se apliquen las dos tercias partes que me pertenecen con más los
} 
Pinto da Vega, eram os principais responsáveis pelo transporte de mercadorias e escravos vindos do porto de Buenos Aires pelo interior da região, rumo a Potosí e a Lima.

As redes comerciais tecidas por Diego da Vega não poderiam deixar de alcançar a América portuguesa e Lisboa. No reino e em seus domínios ultramarinos, Vega mantinha procuradores e credores que permitissem a manutenção da dinâmica comercial rumo ao Rio da Prata. O caso mais latente ocorreu em 1618, quando da divisão da província do Rio da Prata com o Paraguai (ou Guairá) e da nomeação pelo monarca do novo governador. Com anuência do tesoureiro do Rio da Prata e do governador que se dirigia à América espanhola proveniente de Lisboa para assumir o seu cargo, Vega foi capaz de transportar, em navios soltos do sistema da Carrera de Indias, 300 mil ducados em mercadorias. Seu principal credor em Lisboa foi Jorge Lopes Correa e, na Bahia, Francisco de Barrios.

Ao que parece, Barrios era um respeitado negociante na sede do Estado do Brasil. Costumava despachar mercadorias rumo a Buenos Aires e possuía residência próxima ao porto de Salvador para armazenar os produtos que chegavam do além-mar em seu nome. No final do século XVI, Francisco de Barrios costumava transportar para Buenos Aires, em navios de avisos - rápidos bergantins que serviam para o envio de notícias -, encomendas de mercadorias e escravos procedentes de Pernambuco. ${ }^{12} \mathrm{Na}$ época, certamente Barrios possuía o apoio do governador-geral do Brasil, Dom Luís de Sousa, e, especialmente, do capitão-mor Vasco de Sousa.

Não é surpresa constatar que, antes de Dom Luís, outros governadores do Estado do Brasil também mantivessem relações comerciais com mestres de navios ligados a vecinos de Buenos Aires. Em 1616, o governador-geral Gaspar de Sousa deu permissão aos espanhóis Jacome d'Aroso e Pero de Baldes para partirem de Olinda rumo ao proibido porto, no Rio da Prata. Não era a primeira vez que Baldes tratava em Buenos Aires, tendo levado para as "costas do Brasil", em 1615, frutos de la tierra (farinhas, sebo e carne-seca) e couros de vecinos. ${ }^{13}$

Em denúncia de 1618 realizada por um cabo de esquadra do forte e guarda dos navios do porto de Salvador, as embarcações que participavam das rotas para Buenos Aires eram aguardadas com expectativa devido à prata que poderiam carregar. O militar presenciara uma

cuarenta ducados de la licencia y los derechos de aduanilla en conformidad del dicho asiento y cedulas reales despachadas en su conformidad [...]". In: Archivo General de Indias, Escribanía de Cámara y Justicia del Consejo de Indias, Comisiones de la Audiencia de Buenos Aires - Escribanía 880A, fls. 124verso e fls. 22verso-23.

12 TRELLES, Manuel Ricardo. Registro Estadístico de Buenos Aires (1863), 1865. p. 37. Tomo 2.

${ }^{13}$ A aventura desta dupla de comerciantes continuou pelo Atlântico. Com a justificativa de que haviam enfrentado forte tormenta na sua partida do Rio da Prata, Baldes e Aroso arribaram ao Rio de Janeiro e, assim, adiaram o pagamento de suas dívidas deixadas em Pernambuco (apenas em frete, os comerciantes teriam recebido mais de mil patacas). Em terras fluminenses comercializaram couros de Buenos Aires por farinhas e fazendas. Provavelmente, ainda com alguma prata potosina, adquirida ilegalmente em Buenos Aires, não quiseram retornar às graças do governador-geral, seguindo diretamente para Angola. Após a compra de escravos com os metais preciosos contrabandeados nos couros do porto semiaberto, foram descobertos e presos. Comtra Pero de Baldes. In: SALVADO, João Paulo; MIRANDA, Susana Münch (ed.). Livro Primeiro do Governo do Brasil (1607-1633). Brasília: Centro de História e Documentação Diplomática, MRE, 2001. p. 170-179. TRELLES, Manuel Ricardo (Org.). Registro Estadístico de Buenos Aires (1864). Tomo 2. Buenos Aires: "El Nacional", 1866. p. 6. 
vez à chegada de grande quantidade do metal precioso, vindo do Rio da Prata, no navio do lisboeta com a alcunha de El Payano. ${ }^{14} \mathrm{O}$ capitão-mor Vasco de Sousa costumava manter sociedade com esses comerciantes e era amigo do governador do Rio da Prata, obtendo permissão para embarcar barris de vinho para serem vendidos na América espanhola. 0 próprio capitão-mor teria confidenciado a um soldado do porto de Salvador que, dessa forma, obteria alguma prata potosina para quitar dívidas na Bahia.

Em outra denúncia do mesmo ano, o familiar do Santo Ofício de Salvador, Fretes de Brito, afirmou que, nos navios que chegavam à Bahia, desembarcava-se certa quantidade de prata destinada para alguns de seus moradores. Entre eles estava justamente Francisco de Barrios. Segundo Brito:

[...] es cosa muy sabida en esta ciudad [Salvador] como los navíos que vienen del dicho puerto de Buenos Aires vienen remitidos al dicho capitán Francisco de Barrios y que en su casa que está fuera de la ciudad media legua se descarga la plata que traen los dichos navíos y que la más pasa por su mano en lo cual entiende este testigo y tiene por cierto que se hace fraude a Su Majestad porque esta plata viene por registrar y sin pagar derechos y que a cada año viene mucha cantidad y esto lo sabe este testigo porque ha treinta años que vive y reside en esta ciudad y ha estado en el dicho puerto de Buenos Aires donde estuvo y en el Perú dos años poco más o menos y trató con un deudo suyo difunto de comprar y vender algunos negros $[\ldots] .{ }^{15}$

Em carta enviada em 1619 ao juiz de comissão (investigador) do Conselho das Índias, o teniente de gobernador de Tucumán suplicou, com certo teor de alarde e ironia, um maior controle das atividades comerciais mantidas por Diego da Vega devido aos danos que estava causando ao monopólio comercial de Lima:

[...] el gran daño y detrimento que resulta a la real hacienda y derechos de Su Majestad porque si esto no se remedia totalmente cesará el comercio y navegación por Cartagena y por Lima y será total destrucción si el dicho puerto no se remedia para cuyo remedio conviene que de el puerto se quite a Diego da Vega y de la Bahia al dicho Francisco de Barrios y de Lisboa al dicho Jorge Lopes Correa porque es un azote como lo dice su apellido y son las personas que trajinan y tienen la masa de mercadurías, plata y moneda con que está destruida la Real Hacienda $[\ldots] \cdot{ }^{16}$

A influência comercial de Vega em Buenos Aires impressiona. Segundo o então governador do Rio da Prata e Paraguai, Hernandarias de Saavedra, por volta de 1615, Vega teria mais de 200 mil pesos de caudal (cabedal). Tudo teria sido obtido através do comércio no porto. De acordo com o governador, unido a parentes e amigos ele conseguia manter "[...]

\footnotetext{
14 Provavelmente, tratava-se do mestre do navio São Francisco, Mateo Palhano. Em agosto de 1615, esteve na Bahia para comercializar frutos de la tierra em nome do vecino Antonio Gutiérrez Barragán, influente comerciante de Buenos Aires, futuro regidor do Cabildo e parente de portugueses. In: Archivo General de la Nación (Argentina), Registros de Navíos, Navío La Concepción, 1615, sala 9, 45-5-3, fl. 11. ${ }^{15}$ Archivo General de Indias, Escribanía de Cámara y Justicia del Consejo de Indias, Comisiones de la Audiencia de Buenos Aires - Escribanía 880B, fls. 257v-258.

${ }^{16}$ Archivo General de Indias - Escribanía 880B, fls. 567v-568v.
} 
publicas tiendas en este reino y por las otras [...] en los del Brasil, reino de Portugal, Angola, Flandres y otras provincias $[\ldots]{ }^{\prime \prime} .{ }^{17}$ Muitas das mercadorias, por sua vez, permaneciam estocadas em conventos ou no colégio da Companhia de Jesus. ${ }^{18}$ Estes lugares religiosos, com outra jurisdição, não podiam sofrer interferências da administração laica.

Até mesmo o teniente general da cidade de Esteco, na província de Tucumán (ponto de parada de viajantes rumo a Potosí), encaminhou uma denúncia exagerada ao Conselho das Índias informando que todos os moradores do porto rio-platense estavam vinculados a Diego da Vega,

[...] que tiene tiraneada la republica del dicho puerto de Buenos Aires por la mucha plata que trajina en la Bahia por mano de Jorge Lopes Correa con cuya industria de ambos a dos los dichos Barrios y Correa es publico y notorio la maquina de navíos de negros y ropa de Castilla que entran y salen por el dicho puerto $[\ldots] .^{19}$

Esse repúdio à presença de lusitanos como Vega em Buenos Aires ou nos interiores de Tucumán repousava numa luta particular de controle de uma lucrativa rota comercial, do Atlântico rumo ao Alto Peru, mantida em grande medida por homens de negócios, moradores da região, envolvidos com oficiais régios. Por isso, quando da Restauração portuguesa, o temor do Cabildo de Buenos Aires e do governador interino do Rio da Prata, com a dita usurpação do trono português da monarquia espanhola, não poderia centrar-se num repúdio desenfreado aos portugueses. O significativo número de lusitanos estantes ou moradores na cidade não se traduzia numa ameaça ao território hipano-americano. O Rio da Prata ganhou importância devido aos próprios interesses locais em manter alianças comerciais com as "costas do Brasil".

Em 1641, mesmo com o temido alzamiento dos Braganças, nota-se que a presença lusitana era bem-vinda. As disputas internas em Buenos Aires, ao longo da primeira metade do século XVII, apesar de muitas vezes desencadear uma aparente cisão entre lusitanos e espanhóis na região, consistia, na prática, na formação de bandos coesos detentores de poupanças sociais, cujos interesses giravam em torno do monopólio comercial no porto. Envolvidos nos negócios, os lusitanos também tiveram papel fundamental na constituição social da cidade e nas políticas locais para a administração na região.

Apesar da historiografia sobre o tema insistir na dicotomia existente entre lusitanos e espanhóis - conhecidos como confederados e beneméritos - no porto de Buenos Aires, ao longo do século XVII, é difícil discernir grupos endógenos de portugueses na cidade voltados

\footnotetext{
17 Archivo General de Indias - Escribanía 880A, fl. 94.

18 Esta prática também foi comum na Bahia, guardando-se mercadorias trazidas pelo governador do Rio da Prata, Dom Diego de Góngora, nos conventos da Companhia de Jesus da cidade. Archivo General de Indias - Escribanía, 880B.

19 É importante ressaltar que Coleta Xirón também foi advogado de presos do Santo Ofício na cidade de Sevilha e, em Buenos Aires, manteve alianças com o governador Hernandarias de Saavedra, defensor de interesses comerciais no porto contra Diego da Vega. Archivo General de Indias - Escribanía 880A, fl. 95.
} 
unicamente para o comércio. Pelo interesse comercial com portos do Estado do Brasil e pela forte presença de negociantes lusitanos na região rio-platense, os portugueses acabaram fazendo parte de suas imbricações sociais, participando como contrabandistas, vecinos e obtendo, até mesmo, cargos administrativos no Cabildo. Zacarias Moutoukias chama atenção para o fato de que apesar da existência de uma disputa por interesses tão diversos entre os beneméritos e confederados, em 1640 estes dois grupos não passavam de duas redes de notáveis que apresentavam características similares e profundamente interconectadas. ${ }^{20}$

Logo após a segunda fundação de Buenos Aires, em 1580, esses grupos aparentemente dicotômicos não são tão fáceis de discernir entre os que estavam a favor da presença portuguesa e os que lutaram contra ela pelo controle comercial do porto. As redes de interesses formadas pelas relações luso-espanholas em Buenos Aires permitiram um grau de controle maior das rotas comerciais com o Alto Peru e o Atlântico e das formas de negociação com Lima e a Coroa espanhola. É por meio dessas relações sociais e econômicas, muitas vezes em conformação com as diretrizes do centro administrativo colonial, que a presença lusitana em Buenos Aires e seu comércio com portos do Estado do Brasil podem ser compreendidos.

Os portugueses, portanto, não foram elementos externos ou complementares à dinâmica comercial no Rio da Prata, mas parte estrutural e instituinte dessas relações. Os recursos econômicos por si só não explicam a autonomia e a hegemonia de uma elite local em relação ao comércio em Buenos Aires e no Atlântico Sul. Faz-se necessário entender as imbricações políticas e sociais de lusitanos na região rio-platense.

Quando, em 1615, o Cabildo de Buenos Aires decidiu criar uma lista para a distribuição das licenças comerciais para navegação (reparticiones para navegar), dividiu os vecinos por mérito da conquista - os beneméritos. A lista foi formada por aqueles que constituíam o "Cabildo e primeros pobladores" e, em seguida, os "segundos", "terceros" e "ultimos pobladores". Entre os cabildantes estava o conhecido sócio de Vega, Juan de Vergara, e Diego de Trigueros e Francisco de Manzanares. Todos eles estavam ligados a comerciantes e vecinos portugueses. Nessa mesma lista está o primer poblador Anton Higueras de Santana, um dos fundadores da cidade, cuja filha casou-se com o português Francisco Rodriguez. O benemérito Higueras era proprietário de um navio e mantinha constantes contatos comerciais com o Brasil. $^{21}$

As redes sociais constituídas em Buenos Aires e região ficam ainda mais claras com o chamado registro do desarme dos portugueses. Em 1643, o novo governador, Dom Gerónimo Luis de Cabrera, ${ }^{22}$ apresentou à cidade um bando do vice-rei, marquês de Mancera, em que ordenava a todos os portugueses:

\footnotetext{
20 MOUTOUKIAS, Zacarias. Contrabando y control colonial en el siglo XVII. Buenos Aires: Centro Editor de América Latina, 1988.

${ }^{21}$ BIEDMA, José Juan. Acuerdos del Extinguido Cabildo de Buenos Aires. Libros II y III (1614-1617). Buenos Aires: Talleres Gráficos de la Penitenciaria Nacional, 1908. p. 211-216. Tomo 3.

22 Dom Gerónimo Luis de Cabrera era o neto do fundador da cidade de Córdoba e parente de Hernandarias (governou o Rio da Prata e Paraguai nos anos de 1596-1598, 1602-1609, 1615-1618 e foi governador da província do Paraguai até 1621). Encomendero e com alianças parentais pela região,
} 
[...] que residen en esta ciudad, moradores, estantes y habitantes en ella y su jurisdicción [...] registrar y dar razón de sus nombres, apellidos, naturalezas, edades, ofícios, estados, haciendas y familias, y del tiempo en que adentrararon en este puerto, y con que licencia vinieron a él $[\ldots] \cdot{ }^{23}$

Apresentaram-se nas cidades de Buenos Aires, Santa Fé e Corrientes um total de 172 portugueses. No porto de Buenos Aires, foram registrados 108 lusitanos (pelo menos $83 \%$ sem licença) entre marinheiros, vecinos, criollos com descendência lusitana e mulheres portuguesas ou casadas com lusitanos.

Se desse número de portugueses que estavam em Buenos Aires no ano de 1643, retirarmos: a) os marinheiros que haviam acabado de chegar e, provavelmente, estavam de passagem pela cidade; b) as oito esposas que não viam seus maridos há anos; c) os três criollos descendentes de portugueses; encontramo-nos diante da seguinte situação:

Portugueses em Buenos Aires (1643)

\begin{tabular}{|l|l|}
\hline casado com criolla, filha ou neta de conquistador & 20 \\
\hline casado com criolla, filha de espanhol & 20 \\
\hline casado com criolla, filha de pai e mãe português & 11 \\
\hline $\begin{array}{l}\text { casado com criolla, filha de pai ou mãe } \\
\text { português(a) }\end{array}$ & 09 \\
\hline casado com espanhola & 03 \\
\hline casado com portuguesa & 05 \\
\hline casado com criolla (não especificada) & 05 \\
\hline Solteiro & 09 \\
\hline Viúvo & 02 \\
\hline TOTAL & $\mathbf{8 4}$ \\
\hline
\end{tabular}

Fonte: TRELLES, Manuel R. Registro y desarme de portugueses. Revista del Archivo General de Buenos Aires, 1871.

No ano de 1607, antes mesmo do registro do desarme, o então governador Hernandarias seguiu ordens de Cédula Real exigindo o levantamento de todos os estrangeiros moradores e estantes no Rio da Prata: portugueses, franceses, ingleses, flamengos e napolitanos. Registraram-se 51 nomes, sendo 20 de portugueses. Considerando apenas os 16

Cabrera investiu inicialmente numa tentativa de aproximação com as famílias que controlavam o comércio portuário. A intenção do "registro dos portugueses", justificou o governador, era apreender armas "ofensivas y defensivas" como escopetas, espadas e adagas guardadas por portugueses. Na prática, apenas as famílias locais e os lusitanos que se opuseram aos interesses do novo governador foram desarmados, desapropriados de suas chácaras e, em alguns casos, expulsos tierra adientro (principalmente para a cidade de Córdoba ou para o reino do Chile). Archivo General de Indias Escribanía 892B - "Gonçalo Albarez contra el governador...", fl. 3v.

23 TRELLES, Manuel Ricardo. Registro y desarme de portugueses. Revista del Archivo General de Buenos Aires, Tomo 3, 1871, 142-263. 
lusitanos que se declararam casados, seja com filhas de conquistadores ou com portuguesas, e somando-se o memorial do capitão e procurador-geral do Rio da Prata, Manuel de Frías, que afirmou a existência, em 1617, de 200 famílias na cidade, pode-se especular que aquelas mantidas por lusitanos significavam cerca de $8 \%$ da população do porto entre os anos de 1607 a $1617 .{ }^{24}$

De acordo com a historiadora Susana Frías, o tamanho das famílias pertencentes à província do Rio da Prata, ao longo do século XVII, alcançou a média dos 3,5 membros. Para o caso de Buenos Aires, estima-se que, em 1602, sua população não ultrapassou 285 famílias. Número este que se modificou lentamente até 1615, quando a cidade chegou a ter 390 famílias. Em relação aos anos de 1622 a 1664, calcula-se que seu crescimento populacional chegou aos meros $0,68 \% .^{25}$

No período da Restauração portuguesa, provavelmente o número de lusitanos chefes de família alcançou os $20 \%$. De acordo com estudo desenvolvido por Lafuente Machain a partir do registro do desarme de 1641, a proporção de portugueses que se encontrava na cidade de Buenos Aires chegou, nessa época, aos $25 \%$ de sua população. ${ }^{26}$

Entre os registrados estava Diego de Fredes, que dizia ter chegado ao porto havia 52 anos e estar casado com uma criolla nascida no Chile, filha e neta de conquistadores. Era seu terceiro casamento e ele obteve notoriedade na região através do matrimônio, em Córdoba, de sua primeira filha com o capitão Diego Ruiz de Ocaña. O pai deste, Juan Ruiz de Ocaña, teve forte influência em Buenos Aires, sendo um dos seus fundadores juntamente com o teniente Dom Juan de Garay. A família de Ocaña descendia dos primeiros conquistadores que vieram na expedição do adelantado Dom Pedro de Mendoza, fundador da primeira Buenos Aires. Apesar de sua forte influência no porto, Ruiz de Ocaña viveu vários anos em Córdoba, principal cidade intermediária das transações do porto com o interior da região.

O lusitano Diego de Fredes, proprietário de uma tropa de carretas responsável pelo comércio com o interior tucumano, foi um dos tantos responsáveis pela ligação comercial entre Buenos Aires e a cidade de Salta (conhecida pela sua criação de mulas), um dos últimos passos para Potosí. Provavelmente foi entre Buenos Aires e Córdoba que as relações

\footnotetext{
24 Memorial del procurador general de las provincias del Río de la Plata y Paraguai, Capitán Manuel de Frías, al Rey, y visto en Consejo en que expresa las necesidades de dichas tierras y solicita en su nombre nuevas permisiones para navegar al Brasil, Angola y paises circunvecinos, los frutos de la tierra, y en retorno llevar las cosas que tuvieran precisión. In: LEVILLIER, Roberto (coord.). Correspondencia de la Ciudad de Buenos Aires con los reyes de España (1615-1635). Madrid, 1918. Tomo 2. Real Cédula de 2 de abril de 1606, ordenando que se envíe relación de extranjeros residentes en Indias. In: Archivo de la Nación Argentina. Reales Cedulas y Provisiones (1517-1662). Buenos Aires, 1911. Tomo 1. p. 66. Relación de extranjeros en el Rio de la Plata. Año 1607. In: BONORINO, Jorge F. Lima Gonzalez; LUXWURM, Hernan Carlos. Revista del Instituto Historico Municipal de San Isidro, 2001. p. 160-164.

25 FRÍAS, Susana R. La expansión de la población. In: Nueva Historia de la Nación Argentina. Buenos Aires: Planeta, 1999. p. 110.

26 MACHAIN, Ricardo de Lafuente. Los portugueses en Buenos Aires. Siglo XVII. Madrid: Ologáza, 1931.
} 
comerciais de Fredes com os Ruiz de Ocaña se intensificaram, resultando na aliança entre estas famílias. ${ }^{27}$

Outros casos ampliam ainda mais a complexidade das relações familiares e o envolvimento de vecinos espanhóis com portugueses. Na mesma lista do desarme, apresentou-se Antonio Rodriguez Colares, que dizia estar casado com criolla, filha de conquistadores (mas sem especificar seu nome). Anos depois, no padrón de vecinos de 1664, ele continuava a viver na cidade e afirmava que sua esposa era dona Margarita de Escobar. ${ }^{28}$

O bisavô dessa criolla, Alonso de Escobar, foi primer poblador e regidor do Cabildo de Buenos Aires. Em segundas núpcias, quando já havia nascido dona Margarita, Escobar ligou-se a Inés Suárez de Toledo, irmã do então governador Hernandarias de Saavedra.

Por sua vez, o pai de dona Margarita era o influente Antonio Gutiérrez Barragán. Ele fazia, mesmo que esporadicamente, parte do comércio no porto e mantinha alianças com portugueses. Seu tio Bernardo Sánchez, com quem manteve durante alguns anos ligações comerciais, negociava com o português Diego da Vega. Barragán tinha como nora, a cunhada de dona Margarita, uma das filhas do governador interino de 1614, Matheo Leal de Ayala.

Leal de Ayala soube aproveitar-se de um momento singular de quando era governador interino para facilitar a presença de seus familiares e aliados no comércio do porto e no Cabildo da cidade. O vecino comerciante de escravos Hernando de Ribera Mondragón era irmão do alcalde do Cabildo, Sebastián Orduña. Este viria a casar-se com Juana de Manzanares, parente de Matheo Leal de Ayala. Na eleição dos integrantes do Cabildo de 1614, Francisco de Manzanares, marido de Leonor Aguilar, neta de Leal Ayala, foi eleito procurador general e mayordomo do Cabildo. A filha desse casal, Gregoria de Aguilar, era esposa do neto de português e dono de pulpería (casa comercial) Mathias Machado (neto). Seu pai, com mesmo nome, e seu tio Thomás Machado faziam parte de uma rede de comerciantes lusitanos que adquiriram vecindad na cidade.

Os Machados foram casados com as filhas do também lusitano Gil González, o qual era concunhado do vecino e lusitano Amador Báez de Alpoim ("o Velho"). Alpoim chegou ao porto em 1598, na fragata que trouxe o governador Dom Diego Rodrigues de Váldez y de la Banda e sua comitiva. Inclusive o primo de Antonio Barragán, Juan Gutiérrez Barragán, viria a ser sogro de Jacinta Báez de Alpoim, filha do general Amador Báez de Alpoim ("o Moço"). Através das permissões concedidas pelos governadores, os Alpoins comercializaram, no exterior, as mercadorias dos vecinos e introduziram escravos de Angola. Fechando o círculo, ou melhor, essa pequena espiral aqui identificada por uma série de relações familiares com várias outras

27 GAMMALSSON, Hialmar Edmundo. Los pobladores de Buenos Aires y su descendencia. Buenos Aires, 1980. p. 153 e 249.

28 O padrón de vecinos era uma espécie de "censo da cidade" solicitado regulamente pelo monarca. Empadronamiento de esta Ciudad de Buenos Aires, hecho en 07 de enero de 1664. In: TRELLES, Manuel Ricardo. Registro Estadístico de Buenos Aires (1859), Tomo 1, 1860, 46-59. 
ramificações: Báez de Alpoim era irmão de Juan Cabral de Melo, genro do teniente de gobernador Matheo Leal de Ayala. ${ }^{29}$

Difícil é discernir onde estavam os beneméritos - os antigos vecinos, primeros pobladores ou descendentes destes - e os "comerciantes contrabandistas lusitanos" nessas disputas por espaços de poder. Não havia exceções. As redes familiares e de compadrazgo conectavam primeiros pobladores a comerciantes, portugueses ou não.

Além do mais, os próprios beneméritos eram os principais negociantes que, havia décadas, tinham ligações com o Estado do Brasil e estabeleciam as mesmas estratégias comerciais atribuídas aos chamados confederados. De acordo com o estudo de Jorge Gelman, na primeira metade do século XVII, os quinze maiores comerciantes de escravos no porto eram, em sua maioria, vecinos de Buenos Aires, sendo que sete deles ocuparam posições importantes no Cabildo. Além do nome de Vergara, também estavam "antigos" vecinos como Enrique Enriques e Miguel de Rivadeneyra. ${ }^{30}$

Também é difícil analisar o chamado contrabando ejemplar - que historiadores como Raul Molina afirmam existir em seus estudos - nas mãos de um único "grupo de contrabandistas portugueses", ainda mais quando esta prática fazia parte da economia de saberes que movia toda a cidade. ${ }^{31}$ A luta pelo controle do Cabildo, as alianças com tesoureiros e contadores (oficiais régios) e governadores, as constantes visitas de jueces comisionados para investigar os descaminos no porto nada mais são que a própria lógica produtora de um comércio extralegal. ${ }^{32}$

Movendo-se pelas malhas tecidas na cidade, os vecinos ("novos" ou "antigos", portugueses ou não), oficiais régios e governadores exerceram o comércio no porto, abriram possibilidades para outros negócios e continuou-se a permitir a entrada, legalizada ou não, de escravos. ${ }^{33}$

Buenos Aires foi fundada, pela segunda vez, por criollos de Assunção, filhos dos espanhóis conquistadores do Rio da Prata, e a única "nobreza" que seus vecinos poderiam se referir no Seiscentos era a sua descendência com estes primeros pobladores. ${ }^{34}$ Apesar da forte

29 GAMMALSSON, Hialmar Edmundo. Op. cit. p. 187-189, 303-304, 331-322 e 357-358.

30 GELMAN, Jorge. Economia natural - economia monetaria. Los grupos dirigentes de Buenos Aires a princípios del siglo XVII. Anuario de Estudios Americanos, n. 44, 1987, 89-104.

31 Ver especialmente: MOLINA, Raul A. Hernandarias. El hijo de la tierra. Buenos Aires, 1948.

32 Para o conceito de comércio extralegal na Buenos Aires colonial, ver: MOUTOUKIAS, Zacarias. Contrabando y control colonial en el siglo XVII. Buenos Aires: Centro Editor de América Latina, 1988.

33 As leituras históricas sobre a participação lusitana em Buenos Aires apoiam-se especialmente no processo de 19 mil páginas movido por Hernandarias de Saavedra em seu último governo contra o contrabando ejemplar, culminado em 1628, quando retorna à cidade como juiz comissionado. Mais do que uma tentativa de respeito às normas régias, Hernandarias buscou, durante seus governos e como juiz, o controle sobre o comércio no porto.

${ }^{34}$ A primeira cidade-porto de Buenos Aires, erigida sob a ordem do adelantado Mendoza, foi abandonada por volta de 1541 e seus sobreviventes foram deslocados para a nova cidade de Assunção, no Guairá. A importância estratégica da área abandonada, próxima à embocadura do rio da Prata, levou o ouvidor da Audiência de Charcas (Tribunal) e governador do Rio da Prata, Juan Torres de Vera y Aragon, a nomear 
endogamia que costumava haver nas cidades hispano-americanas na busca por manter uma parentela hidalga (mesmo não sendo totalmente castiça), ${ }^{35}$ no caso de Buenos Aires, a preocupação maior esteve nas possibilidades que os novos moradores da cidade, mesmo sendo portugueses, poderiam recriar. O matrimônio teve um importante papel na constituição de interesses econômicos, políticos e sociais; e o Cabildo transformou-se num dos espaços em que as redes de parentesco e cumplicidade permitiram a continuidade de formas de autoridade. ${ }^{36}$

Para o comerciante estrangeiro, pertencer a um ethos mantido por uma elite do porto significou participar, mesmo que muitas vezes indiretamente, dos espaços de poder da cidade. Isto é, integrar-se às ações de uma extralegalidade em Buenos Aires significava criar ou manter redes comerciais, ter amigos na região ou mesmo possuir família. Viver na cidade como vecino fazia parte de uma série de vantagens que envolvia o direito a mercês de terras, à participação em vaquerías e voz no Cabildo. Estes espaços de pertencimento apenas tornavam-se possíveis através da formação de redes que traspassavam o comércio, a política e a sociedade. Formaram-se na Buenos Aires seiscentista exercícios de solidariedade horizontais e verticais que buscaram meios de melhorar as chances individuais e coletivas desses homens. ${ }^{37}$

Ser apenas um rico comerciante na cidade, apesar de sua importância econômica, não proporcionava certezas. Seus negócios, apartados das redes sociais e suas estratégias locais, poderia levá-lo à prisão ou ao desterro. Por outro lado, inserir-se nas ações coletivas familiares significava envolver-se numa economia política de privilégios capaz de protegê-lo e evitar possíveis ações da justiça régia.

Mas, assim como ser apenas um comerciante não trazia maiores garantias, nota-se que o direito à vecindad não produzia, por si só, segurança ao lusitano. Relacionar os negócios do porto ao direito de vecindad, por mais pobre e isolada que a cidade fosse, criava expectativas e possibilidades válidas de participação em redes de cumplicidade locais (e supralocais) capazes de cristalizar práticas extralegais. Foi este desejo de pertencimento e conquista de

Juan de Garay como teniente de gobernador e como novo fundador da cidade em 1580, localizada pouco acima do rio Riachuelo, onde estava sua antiga fundação. GUÉRIN, Miguel Alberto. La organización inicial del espacio peruano. In: TANDETER, Enrique (dir.). Nueva Historia Argentina. La sociedad colonial. Buenos Aires: Sudamericana, 2000. Tomo 2.

35 Já no final do século XVII e início do XVIII, a oposição do patriarca aos enlaces matrimoniais ocorreu, frequentemente, motivada pela diferença racial, nível social ou "moralidade" do candidato e sua desigualdade econômica. Enquanto a Igreja defendeu a liberdade de escolha dos cônjuges, desde 1548 leis civis permitiram aos pais, quando não podiam desfazer o matrimônio sacramentado pela Igreja, deserdar os filhos casados sem o seu consentimento. Em 1644, o bispo de Tucumán já alertava: "Esta tierra és corta, y así hay mucho trabajo en los casamientos, por estar casi imposibilitados por parentescos de consanguinidad y afinidad". BELSUNCE, César A. García. La Familia. In: Nueva História de la Nación Argentina. Buenos Aires: Planeta, 1999. p. 131-136.

36 BERNAL, Manuela C. García. Las élites capitulares indianas y sus mecanismos de poder en el siglo XVII. Anuário de Estudios Americanos, v. 57, n. 1, 2000. p. 89-110.

37 REVEL, Jacques. Prefácio. A história ao rés-do-chão. In: LEVI, Giovanni. A herança imaterial. Trajetória de um exorcista no Piemonte do século XVII. Rio de Janeiro: Civilização Brasileira, 2000. p. 24-33. 
privilégios nas relações de poder locais e de comércio no Império espanhol americano, mesmo após a Restauração portuguesa, que muitos lusitanos buscaram alcançar. Enquanto o forte de Sacramento estabelecia-se em fins do século XVII como uma ameaça militar lusitana diante do estratégico porto de Buenos Aires, na própria região platina e seu interior lusitanos continuaram, mesmo em menor escala, a comercializar gado muar e a envolver-se nas redes parentais ao longo do Setecentos. ${ }^{38}$

Rodrigo Ceballos: Professor adjunto do Curso de História no Centro de Formação de Professores (UFCG). Possui mestrado em História Cultural pela UNICAMP e doutorado em História Social pela UFF. Possui pesquisas e publicações envolvendo a história da América lusoespanhola. Atualmente, estuda as tramas sociais formadoras de uma dinâmica política e econômica nos sertões da capitania da Paraíba do Norte.

38 REITANO, Emir. Los portugueses del Buenos Aires tardocolonial: inmigración, sociedad, familia, vida cotidiana y religion. Tese (Doutorado em História). Facultad de Humanidades y Ciencias de la Educación de la Universidad Nacional de La Plata, La Plata, 2003. 